http://dx.doi.org/10.32929/2446-8355.2021v30n2p149-165

\title{
SISTEMA SOJA E MILHO SAFRINHA CONSORCIADO COM Urochloa ruziziensis: DOIS ANOS DE CULTIVO
}

Anderson Lange ${ }^{1}$, Antonio Carlos Buchelt ${ }^{2}$, Diego Antônio Tolfo ${ }^{3}$, Diouser Dassi ${ }^{4}$, Alexandre Ferreira da Silva ${ }^{5}$, Edilson Cavalli ${ }^{6}$

\footnotetext{
${ }^{1}$ Docente, Solos/fertilidade do solo e nutrição de plantas, Universidade Federal de Mato Grosso/UFMT, Sinop, MT.*paranalange@ hotmail.com

${ }^{2}$ Docente, Solos/fertilidade do solo e nutrição de plantas, Universidade do Estado de Mato Grosso/UNEMAT, Alta Floresta, MT.

${ }^{3}$ Engenheiro Agrônomo, gestão comercial/vendas, Autônomo, Sinop, MT.

${ }^{4}$ Engenheiro Agrônomo, Fazenda e Agropecuária Dassi, Vera, MT.

${ }^{5}$ Pesquisador/EMBRAPA Milho e Sorgo/Sete Lagoas - MG.

${ }^{6}$ Engenheiro Agrônomo, gestão comercial/vendas, Autônomo, Guarantã do Norte, MT.
}

\section{Recebido: 09/04/2021; Aceito: 20/09/2021}

RESUMO: No Estado do Mato Grosso a adubação e correção do solo é realizada predominantemente antes da soja e, o milho safrinha semeado na sequência. Foram avaliados seis manejos da adubação na soja: Ausência de fertilização; Adubação de $400 \mathrm{~kg} \mathrm{ha}{ }^{-1}$ (adubação da fazenda (AF), NPK 00-18-18 na superficie em pré-semeadura); AF em superfície e gessagem; AF no sulco e gessagem; AF em superfície e calagem; AF no sulco e calagem. O milho safrinha foi semeado após a soja e as parcelas divididas ao meio e o fertilizante $\left(250 \mathrm{~kg} \mathrm{ha}^{-1}\right)$ foi misturado à Urochloa ruziziensis, aplicando a mistura em superfície ou enterrada no sulco, sendo que para o tratamento ausência de fertilização na soja foram aplicados $650 \mathrm{~kg} \mathrm{ha}^{-1}$ de fertilizante. Foram avaliadas as variáveis produtivas da soja e do milho e o solo após a colheita da primeira safrinha de milho. As correções e fertilizações não provocam alterações significativas nos componentes de produção e a produtividade final da culturas. A aplicação de gesso movimentou o potássio no perfil do solo, aumentou o teor de cálcio em relação à $\mathrm{CTC}$ e alterou a relação $\mathrm{Ca} / \mathrm{Mg}$ na camada de $0-0,2 \mathrm{~m}$. A Urochloa ruziziensis aplicada em superficie ou incorporada produziu quantidade de massa similar.

Palavras-chave: Adubação de sistema. Integração lavoura-pecuária. Gesso Agrícola. Zea mays. Glycine max

\section{SOYBEAN-MAIZE SECUND CROP SYSTEM INTERCROPPED WITH Urochloa ruziziensis: TWO YEARS OF CULTURE}

\begin{abstract}
In Mato Grosso state, fertilization and soil correction is carried out predominantly before soybeans, and safrinha corn sown in sequence. Six managements of fertilization in soy were evaluated: Absence of fertilization; Fertilization of $400 \mathrm{~kg} \mathrm{ha}^{-1}$ (fertilization of the farm (AF), NPK 00-18-18 on the surface in pre-sowing); Surface AF and plaster; Furrow AF and plaster; Surface AF and liming; AF in the groove and liming. Safrinha corn was sown after soybean and the plots divided in half and the fertilizer $\left(250 \mathrm{~kg} \mathrm{ha}^{-1}\right)$ was mixed with Urochloa ruziziensis, applying the mixture on the surface or buried in the furrow,
\end{abstract}


and for the treatment, absence of fertilization in the soybean was applied $650 \mathrm{~kg} \mathrm{ha}^{-1}$ of fertilizer. The productive variables of soybean and corn and the soil after harvesting the first corn crop were evaluated. The corrections and fertilizations do not cause significant changes in the production components and the final productivity of the crops. Plaster application moved potassium in the soil profile, increased calcium content in relation to CEC and changed the $\mathrm{Ca} / \mathrm{Mg}$ ratio in the 0-0.2 m layer. The Urochloa ruziziensis applied on the surface or incorporated produced a similar amount of mass.

Key words: System of fertilization. Crop-livestock integration. Gypsum. Zea mays. Glycine $\max$

\section{INTRODUÇÃO}

O Estado de Mato Grosso se destaca no cenário nacional como principal produtor de soja e milho e a semeadura do milho ocorre, predominantemente, entre os meses de janeiro e março após o cultivo da soja, época conhecida como cultivo de milho safrinha ou, ultimamente como vem sendo chamado, milho segunda safra. A sua produtividade é bastante afetada pelas limitações de água, radiação solar e temperatura, em estádios avançados de desenvolvimento. No estado o déficit hídrico é o principal fator abiótico limitante ao aumento da produtividade do milho safrinha, principalmente, nas semeaduras mais tardias em solos com baixa estruturação e fertilidade e pobres em cobertura vegetal.

$\mathrm{Na}$ região médio norte do Estado, a adubação do milho safrinha é realizada após sua semeadura com o formulado 20-00-20 (N-P-K), na dose de 300 a $400 \mathrm{~kg} \mathrm{ha}^{-1}$, parcelado ou não, na superfície do solo e esta adubação atualmente não atende a elevada capacidade extrativa da cultura (DUARTE et al., 2018), que pode chegar a $8.000 \mathrm{~kg} \mathrm{ha}^{-1}$. A baixa utilização de insumos ocorre devido o risco de frustação de safra, porém hoje com a adoção de materiais precoces para o cultivo da soja, o intervalo de semeadura do milho tem aumentado, garantindo semeaduras ainda em janeiro e menor risco de déficit hídrico no final do ciclo. Nessa situação os produtores ainda não adequaram-se aos novas extrações e exportações de nutrientes que a cultura necessita, o que pode limitar a produtividade.

Tendo por objetivo minimizar o risco de safra e melhorar a qualidade física, química e biológica do solo, tem-se observado o índice crescente de adoção do consórcio milho safrinha - U. ruziziensis e a realização de práticas de calagem e gessagem nas propriedades da região. O milho consorciado com $U$. ruziziensis no período de safrinha, além de aumentar a produção de palha e favorecer a manutenção da umidade solo pode facilitar o aprofundamento do sistema radicular das culturas anuais semeadas em sucessão, devido aos microcanais formados pelas raízes da forrageira, mortas na dessecação. Além desses benefícios, o consórcio pode contribuir na ciclagem de nutrientes em função da diferente geometria do seu sistema radicular quando comparado com as raízes das culturas anuais. Já a calagem e gessagem visam corrigir o impedimento químico ao crescimento das raízes ocasionado principalmente pela acidez do solo e pela deficiência de cálcio $(\mathrm{Ca})$, magnésio $(\mathrm{Mg})$ e enxofre (S), que tem se tornado limitante. 
Os métodos de aplicação da adubação fosfatada a lanço ou localizada no sulco de semeadura vem sendo discutidos (SOUSA et al., 2016; NUNES et al., 2020) e, na região a prática de aplicação a lanço é muito difundida, devido aos problemas de logística, pois as áreas são grandes, o que deixa a aplicação a lanço em vantagem, devido a economia de tempo em relação a aplicação no sulco, porém sabe-se que a aplicação no sulco pode reduzir a adsorção (LANGE et al., 2019) e aumentar a disponibilidade do adubo. Em virtude da não incorporação e não revolvimento, a necessidade de $\mathrm{P}$ pode ser menor na semeadura direta, reduzindo as perdas pois a aplicação superficial sem incorporação acarreta menor fixação de $\mathrm{P}$, aumentando consequentemente a disponibilidade na camada mais superficial, o que pode ser um risco em áreas sujeitas a déficit hídrico ou em anos em que a chuva cessa precocemente.

Além dos efeitos diretos da calagem, tais como a neutralização da acidez e do alumínio (Al), e o fornecimento de $\mathrm{Ca}$ e $\mathrm{Mg}$ existem os efeitos indiretos, que se manifestam de várias maneiras, como o aumento da disponibilidade do fósforo no solo. A calagem melhora o ambiente químico do solo e neutraliza o alumínio, favorece o desenvolvimento das raízes e a exploração de um maior volume de solo pelo sistema radicular, facilitando a absorção de água e de nutrientes, em especial daqueles que, como o fósforo, têm pouca mobilidade no solo (DUARTE; CANTARELLA, 2008).

Em casa de vegetação se observou que relações $\mathrm{Ca} / \mathrm{Mg}$ 4:1 e 5:1 são favoráveis ao acúmulo de massa radicular, grãos por espiga e produção total (LANGE et al., 2021), observando ainda que na região Médio Norte do MT, há estreitamento desta relação, ficando próxima a 2:1, devido a frequente utilização de calcário dolomitico. Em algumas situações o gesso tem sido recomendado para ajudar na melhoraria das condições químicas dos horizontes subsuperficiais. No Cerrado, a aplicação de gesso é recomendada quando o solo tem teores limitantes de cálcio em subsuperfície $<0,5 \mathrm{cmol}_{\mathrm{c}} \mathrm{dm}^{-3}$ e/ou saturação por alumínio $(\mathrm{m} \%)>20$ (SOUSA; LOBATO, 2004). O gesso tem sido utilizado também como fonte de enxofre (cerca de $13 \%$ de S) e é aplicado em área total em doses de 500 a $1000 \mathrm{~kg} \mathrm{ha}^{-1}$, dependendo da textura do solo (DUARTE; CANTARELLA, 2008).

\section{MATERIAL E MÉTODOS}

O experimento foi realizado durante os anos agrícolas 2011-2012 e 2012-2013, em área comercial da fazenda Agropecuária Dassi, localizada no município de Vera, Mato Grosso, em relevo considerado como moderadamente plano, num Latossolo Vermelho distrófico (LVd) típico argiloso (EMPRESA BRASILEIRA DE PESQUISA AGROPECUÁRIA - EMBRAPA, 2013). O clima predominante da região é classificado como Aw, segundo a classificação de Köppen, com estação seca bem definida, sendo caracterizada pela estiagem rigorosa e período chuvoso bastante intenso. A temperatura média anual oscila entre $20^{\circ} \mathrm{C}$ e $38^{\circ} \mathrm{C}$, tendo como média $26^{\circ} \mathrm{C}$ e precipitação média anual de $2.427 \mathrm{~mm}$. A precipitação mensal e a temperatura média para o período de condução do estudo estão abaixo (Figura 1).

Em setembro de 2011 foi retirada uma amostra composta na camada 0-20 cm de profundidade, analisado segundo metodologia da EMBRAPA (2009), que apresentou os seguintes resultados: $\mathrm{pH}_{\mathrm{H} 2 \mathrm{O}}=6,1, \mathrm{P}_{\mathrm{mel}}=4,1 \mathrm{mg} \mathrm{dm}{ }^{-3}, \mathrm{~K}=68,1 \mathrm{mg} \mathrm{dm}^{-3}, \mathrm{Ca}^{2+}=3,9 \mathrm{cmol}_{\mathrm{c}}$ 
$\mathrm{dm}^{-3}, \mathrm{Mg}^{2+}=1,4 \mathrm{cmol}_{\mathrm{c}} \mathrm{dm}^{-3} ; \mathrm{Al}^{3+}=0,0 \mathrm{cmol}_{\mathrm{c}} \mathrm{dm}^{-3} ; \mathrm{H}+\mathrm{Al}=4,7 \mathrm{cmol}_{\mathrm{c}} \mathrm{dm}^{-3}, \mathrm{MO}=28 \mathrm{~g} \mathrm{dm}^{-3}$, $\mathrm{V}=54 \%$ e teor de argila $=450 \mathrm{~g} \mathrm{~kg}^{-1}$.
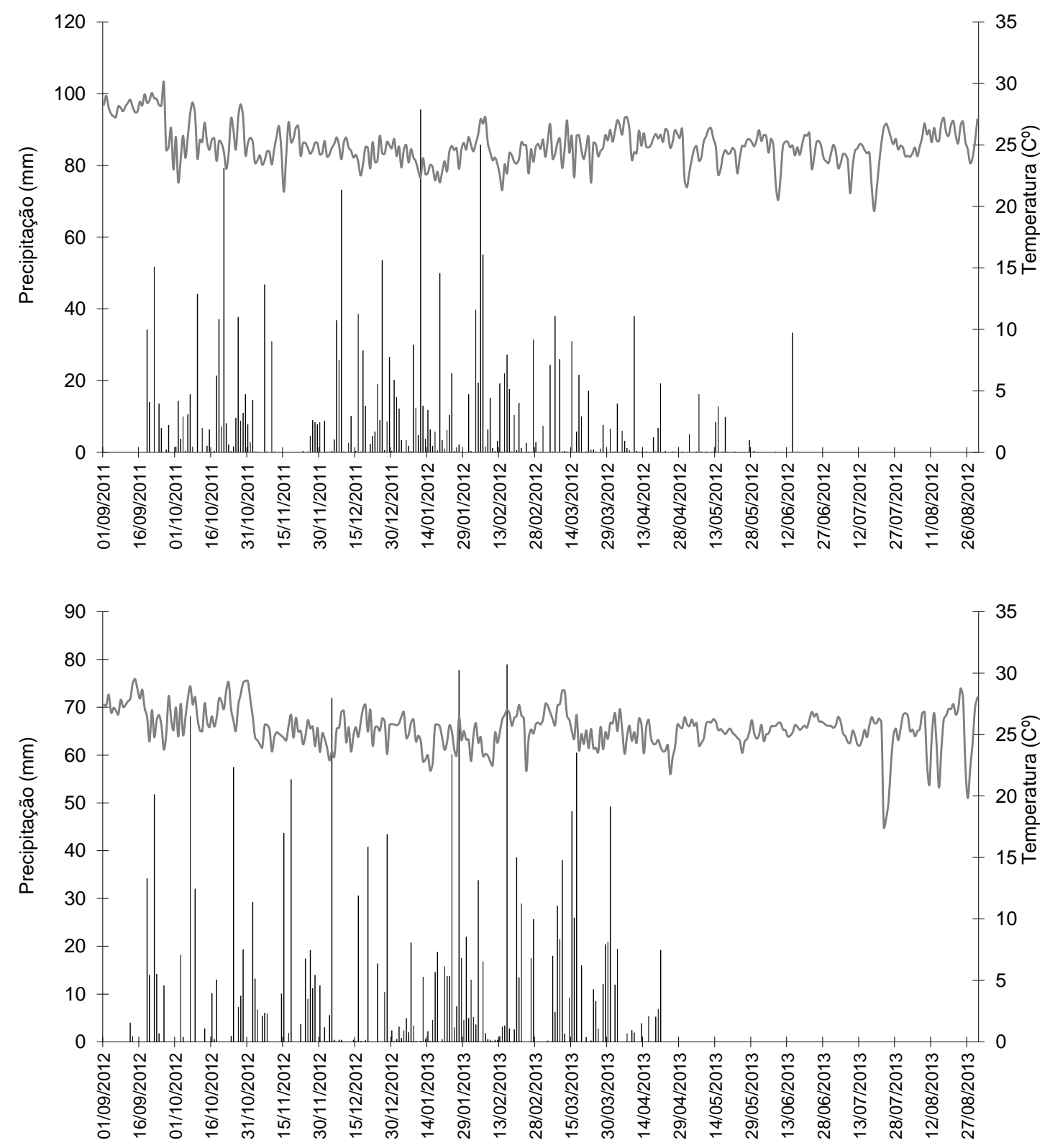

Figura 1. Dados climatológicos de precipitação e temperatura média durante a condução do experimento na safra 2011-2012 e 2012-2013. Vera - MT. Climatological data of precipitation and average temperature during the conduct of the experiment in the 2011-2012 and 2012-2013 harvest. Vera - MT.

Fonte: Autoria própria. Own authorship.

O delineamento experimental utilizado foi o de blocos ao acaso, sendo que na soja foram seis tratamentos em parcelas de $7 \mathrm{~m} \times 15 \mathrm{~m}$, a saber:

(1) ausência de adubação e corretivos na soja;

(2) manejo tradicional de adubação da fazenda, em que não foi realizada a correção do solo, e a adubação foi realizada a lanço, em 23/09/2011, antecedendo a semeadura da soja 
(22/10/2011), com $400 \mathrm{~kg} \mathrm{ha}^{-1}$ do formulado $00-18-18+8 \mathrm{~S}+16 \mathrm{Ca}+0,8 \mathrm{Zn}+0,16 \mathrm{~B}+0,07 \mathrm{Cu}$ $+0,18 \mathrm{Mn}$

(3) 3,0 t ha ${ }^{-1}$ de gesso agrícola em pré-semeadura no dia 23/09/2011 a lanço em área total e adubação de semeadura em superfície conforme manejo da fazenda;

(4) 3,0 t ha ${ }^{-1}$ de gesso agrícola em pré-semeadura no dia 23/09/2011 a lanço em área total e adubação de semeadura enterrada no sulco;

(5) 2,0 t ha $\mathrm{ha}^{-1}$ de calcário em pré-semeadura no dia 23/09/2011 a lanço em área total e adubação de semeadura em superfície conforme manejo da fazenda;

(6) 2,0 t ha-1 de calcário em pré-semeadura no dia 23/09/2011 a lanço em área total e adubação de semeadura enterrada no sulco.

Como corretivo foi utilizado o calcário dolomítico, com $\mathrm{CaO}$ (29\%), $\mathrm{MgO}(19 \%)$ e PRNT-76\% e gesso agrícola, com Ca (17\%) e S (14\%).

Para semear a soja utilizou-se o espaçamento de 0,45 m entre linhas e o material genético M8867 RR (Aurora ${ }^{\circledR}$ ), de ciclo semi-precoce, grupo de maturação 8.8 (125 dias), 12 plantas por metro linear e população final de 260 mil plantas por hectare. Os tratamentos fitossanitários e controle das plantas daninhas foram realizados conforme a necessidade da cultura, sendo efetuados junto ao manejo da fazenda, tratos comuns de lavoura da região.

A colheita da soja foi realizada no final do mês de fevereiro de 2012. Para isso foram colhidas quatro linhas de quatro metros. Uma sub amostra de 10 plantas foi retirada para mensurar: (a) altura das plantas; (b) número de vagens por planta; (c) número de grãos por vagem,; (d) massa de mil grãos secos em estufa e correção para 13\% de umidade; (e) altura de inserção da primeira vagem,; (f) produtividade, corrigido para $13 \%$ umidade.

Após este procedimento, em 01/03/2012 as parcelas foram divididas ao meio no sentido do comprimento, com 3,5 $\mathrm{m}$ de largura e $15 \mathrm{~m}$ de comprimento, gerando um novo fator para a cultura do milho (subparcelas). Nestas realizou-se a semeadura do milho de forma mecanizada e distribuição da mistura fertilizante/sementes de $U$. ruziziensis, da seguinte forma:

(1) de forma mecanizada: a mistura foi incorporada no sulco de semeadura do milho a uma profundidade de cinco centímetros;

(2) a mistura foi aplicada a lanço e em área total, antes de semear o milho, simulando a aplicação mecanizada a lanço em pré-semeadura. Este método leva em consideração que parte das sementes de $U$. ruziziensis serão incorporadas na operação mecânica de semeadura do milho.

A quantidade de sementes da forrageira foi de $10 \mathrm{~kg} \mathrm{ha}^{-1}$ com VC de $36 \%$, totalizando 360 pontos de valor cultural por hectare. Para a adubação, nos tratamentos em que foram aplicados $400 \mathrm{~kg} \mathrm{ha}^{-1}$ do formulado no cultivo da soja foi adicionado ao milho mais $250 \mathrm{~kg}$ $\mathrm{ha}^{-1}$ do formulado 00-18-18, perfazendo no sistema soja-milho $650 \mathrm{~kg} \mathrm{ha}^{-1}$ do formulado, segundo manejo da fazenda. No tratamento controle em que não foi aplicado fertilizante na soja, foram aplicados os $650 \mathrm{~kg} \mathrm{ha}^{-1}$ do formulado 00-18-18 $(+8 \mathrm{~S}+16 \mathrm{Ca}+0,8 \mathrm{Zn}+0,16 \mathrm{~B}+$ $0,07 \mathrm{Cu}+0,18 \mathrm{Mn})$, perfazendo assim em todos os tratamentos a quantia de $650 \mathrm{~kg} \mathrm{ha}^{-1}$ do formulado 00-18-18 ao final da safra. O espaçamento entrelinhas foi similar à soja, com 0,45 
$\mathrm{m}$, com três sementes por metro linear e população de aproximadamente 65.000 plantas por hectare.

O hibrido de milho utilizado na área experimental foi o 2B655HX da Dow AgroSciences ${ }^{\circledR}$, que é um hibrido triplo precoce para médio e alto investimento, indicado para semeaduras no verão e segunda safra, seu ciclo de cultivo é de aproximadamente 145 dias. Aos 30 dias após a emergência do milho (DAE), foi realizada a aplicação em cobertura de 200 $\mathrm{kg} \mathrm{ha}^{-1}$ do formulado 20-00-20 em toda área, conforme o manejo da fazenda. Não foi realizado nenhum controle químico ou cultural na $U$. ruziziensis.

Foram realizadas as seguintes mensurações na cultura do milho: (a) altura de plantas e a (b) altura de inserção de espiga, (c) número de fileiras de grãos por espiga (d) número de grãos por fileira (e) número de grãos por espiga (f) estande de plantas; (g) produtividade foi obtida pela debulha mecanizada através de trilhadeira acoplada ao trator e a tomada de força, sendo as espigas colhidas na área útil de cada parcela (20 metros lineares) trilhadas. A umidade dos grãos foi conhecida pelo método da estufa, e o rendimento dos mesmos teve seu valor corrigido para $13 \%$ de umidade; (h) massa de mil grãos à 13\% de umidade. A colheita do milho foi realizada em 26/07/2012, correspondendo a 146 DAE.

A produtividade de massa seca da $U$. ruziziensis foi determinada 50 dias após a colheita do milho, sendo ceifadas duas amostras de $1 \mathrm{~m}^{2}$ de cada, em cada subparcela com o auxílio de um quadrado de madeira de $1 \mathrm{~m} \times 1 \mathrm{~m}$. Após o corte, a forrageira foi levada para a estufa com circulação de ar forçada, com temperatura de $65^{\circ} \mathrm{C}$, por cerca 72 horas, e depois de quantificado o material e os dados foram transformados em $\mathrm{kg} \mathrm{ha}^{-1}$.

Antes do início das chuvas, em setembro de 2012 foram colhidas amostras de solo na profundidade de $0-0,1 \mathrm{~m}$ e $0,1-0,2 \mathrm{~m}$, em todas as parcelas onde se realizou o manejo da adubação da soja, ou seja, nos seis tratamentos inicias. Para isto foram colhidas 10 amostras simples dentro de cada parcela, já que a fonte de variação para a fertilidade do solo foi apenas o manejo da fertilização na pré-semeadura ou semeadura da soja. As análises químicas de solo realizadas seguiram o método padrão descrito em EMBRAPA (2009).

Para a safra 2012-2013 ( $2^{\circ}$ ano do estudo), manteve-se o manejo da fazenda na área do experimento, sem interferência. Repetiram-se as coletas na soja e no milho, de mesma forma que no primeiro ano, sendo que no milho manteve-se o esquema inicial do experimento, com os seis tratamentos iniciais, já que o objetivo era avaliar o efeito residual das correções/adubações da soja, já que a $U$. ruziziensis em meio ao milho no primeiro ano ficou homogênea, conforme os dados mostraram. Para a cultura da soja os dados, apesar de representativos e processados, foram perdidos, devido a um arquivo corrompido. Para o milho os dados foram processados e analisados. No segundo ano do estudo, a soja foi semeada em outubro e colhida em final de fevereiro e recebeu $400 \mathrm{~kg} \mathrm{ha}^{-1}$ do formulado 00-18-18 antes da semeadura, em superfície. O milho foi semeado na primeira semana de março de 2013 e recebeu $200 \mathrm{~kg} \mathrm{ha}^{-1}$ de 20-00-20 aos 30 dias após a emergência (DAE), também em superfície, sendo que neste fertilizante foi adicionada a $U$. ruziziensis novamente, nas mesmas medidas do primeiro ano. Neste ano o milho não recebeu adubação de semeadura. 
Os dados foram avaliados através da análise variância simples, sendo comparadas pelo teste de F. As médias foram comparadas pelo teste de Tukey no nível de $10 \%$ de probabilidade, pelo programa SISVAR ${ }^{\circledR}$ (FERREIRA, 2019).

\section{RESULTADOS E DISCUSSÃO}

Nenhuma das variáveis apresentou diferença significativa na cultura da soja em função dos modos de aplicação do fertilizante e diferentes corretivos de solo no primeiro ano (Tabela 1). A altura das plantas (AP) variou entre $74,8 \mathrm{~cm}$ para a ausência de fertilização a $86,2 \mathrm{~cm}$ com a aplicação de gesso e adubação superficial. Os resultados foram semelhantes aos obtidos por Bergamin et al. (2008), que ao estudar a adubação de semeadura no sulco ou a lanço antecipada verificaram que a AP mostram-se indiferente quanto ao modo de aplicação do fertilizante. A altura de inserção da primeira vagem (AIV) de soja é uma característica agronômica importante à operação de colheita mecânica. Neste trabalho a variação foi entre 21,8 e 25,3 cm, não sendo influenciada pelos tratamentos. Aparentemente não houve limitação de $\mathrm{P}$ para as plantas que não receberam adubação ou para aquelas que o $\mathrm{P}$ foi aplicado em superfície, o que não influenciou esta característica, o que corrobora com estudo de variação de doses de $\mathrm{P}_{2} \mathrm{O}_{5}$ no solo, de 0 a $200 \mathrm{~kg} \mathrm{ha}^{-1}$, não havendo influência nesta variável (VALADÃO JUNIOR et al., 2008).

Tabela 1. Altura de planta (AP), altura de inserção da primeira vagem (AIV), número de vagens por planta (NVP), número de grãos por planta (NGP), massa de 1000 grãos (M1000G) e produtividade (PD) da soja em diferentes sistemas de manejo da adubação. Vera-MT, safra 2011/2012. Plant height (AP), insertion height of the first pod (AIV), number of pods per plant (NVP), number of grains per plant (NGP), mass of 1000 grains (M1000G) and productivity $(P D)$ of soy in different manure management systems. Vera-MT, 2011/2012 harvest.

\begin{tabular}{lcccccc}
\hline \multirow{2}{*}{ Tratamentos } & AP & AIV & NVP & NGP & M1000G & PD \\
\cline { 2 - 7 } & \multicolumn{2}{c}{$---\mathrm{cm}---$} & & & $\mathrm{g}$ & $\mathrm{kg} \mathrm{ha}^{-1}$ \\
\hline $\begin{array}{l}\text { Ausência de correção e } \\
\text { adubação }\end{array}$ & $74,9 \mathrm{a}$ & $22,2 \mathrm{a}$ & $60,1 \mathrm{a}$ & $125,8 \mathrm{a}$ & $99,7 \mathrm{a}$ & $3597,6 \mathrm{a}$ \\
PK superficial (manejo & $78,0 \mathrm{a}$ & $21,9 \mathrm{a}$ & $67,1 \mathrm{a}$ & $147,1 \mathrm{a}$ & $102,2 \mathrm{a}$ & $3947,5 \mathrm{a}$ \\
fazenda) & & & & & & \\
Gesso+PK superficial & $86,3 \mathrm{a}$ & $24,7 \mathrm{a}$ & $56,9 \mathrm{a}$ & $123,6 \mathrm{a}$ & $103,2 \mathrm{a}$ & $3765,0 \mathrm{a}$ \\
Gesso+PK incorporado & $81,6 \mathrm{a}$ & $24,5 \mathrm{a}$ & $65,0 \mathrm{a}$ & $132,8 \mathrm{a}$ & $104,7 \mathrm{a}$ & $4008,8 \mathrm{a}$ \\
Calcario+PK superficie & $84,6 \mathrm{a}$ & $25,2 \mathrm{a}$ & $55,7 \mathrm{a}$ & $123,0 \mathrm{a}$ & $108,2 \mathrm{a}$ & $3839,3 \mathrm{a}$ \\
Calcario+PK incorporado & $77,6 \mathrm{a}$ & $24,4 \mathrm{a}$ & $67,1 \mathrm{a}$ & $150,1 \mathrm{a}$ & $106,5 \mathrm{a}$ & $3630,9 \mathrm{a}$ \\
\hline Média & 80,5 & 23,8 & 62,0 & 133,7 & 104,1 & 3798,2 \\
\hline CV & 7,14 & 8,67 & 16,51 & 17,20 & 4,19 & 6,53 \\
\hline
\end{tabular}

Nota: $\mathrm{PK}=400 \mathrm{~kg} \mathrm{ha}^{-1}$ do formulado 00-18-18 + 8S+ $16 \mathrm{Ca}+0,8 \mathrm{Zn}+0,16 \mathrm{~B}+0,07 \mathrm{Cu}+0,18 \mathrm{Mn}$; Gesso = 3,0 t $\mathrm{ha}^{-1} \mathrm{e}$ Calcário 2,0 $\mathrm{t} \mathrm{ha}{ }^{-1}$. Médias seguidas da mesma letra, nas colunas, não diferem, estatisticamente, entre si, a $10 \%$, pelo teste Tukey. $P K=400 \mathrm{~kg} \mathrm{ha}^{-1}$ of the formula $00-18-18+8 S+16 \mathrm{Ca}+0.8 \mathrm{Zn}+0.16 \mathrm{~B}+0.07 \mathrm{Cu}+$

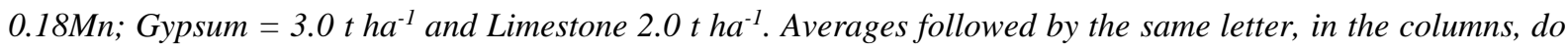
not differ, statistically, from each other, by 10\%, by the Tukey test.

Fonte: Autoria própria. Own authorship. 
A adubação em superfície é questionada em relação ao seu aproveitamento pela cultura, pois argumentasse que pode haver fornecimento inadequado tanto de $\mathrm{P}$ quanto de $\mathrm{K}$ devido ao menor contato planta fertilizante. A carência de $\mathrm{P}$ e $\mathrm{K}$ causa redução no número de legumes por planta, na massa dos grãos e por final na produtividade (FOLONI; ROSOLEM, 2008; VALADÃO JUNIOR et al., 2008). Isto aparentemente não ocorreu no trabalho, já que o número de vagens por planta (NVP), a massa de 100 grãos (M100G) e a produtividade (PD) foram similares nos tratamentos, alcançando produtividade média final de $3798 \mathrm{~kg} \mathrm{ha}^{-1}$ (63 sc $\left.\mathrm{ha}^{-1}\right)$.

A produtividade variou entre $3598 \mathrm{~kg} \mathrm{ha}^{-1}$ na ausência de correção e adubação na soja até $4.009 \mathrm{~kg} \mathrm{ha}^{-1}$ para a aplicação de gesso e incorporação do fertilizante em semeadura. Observa-se que na ausência de fertilização na soja a produtividade foi $241 \mathrm{~kg} \mathrm{ha}^{-1}$ menor relativamente aos demais manejos $\left(3.838 \mathrm{~kg} \mathrm{ha}^{-1}\right)$, o que pode ser resultado da carência de algum nutriente aplicado, mas este resultado não foi significativo. A aplicação de calcário ou gesso não apresentou resultado significativo na soja no primeiro ano, o que pode ser visto comparando em relação ao manejo adotado na fazenda, com fertilização superficial, produzindo $3.947 \mathrm{~kg} \mathrm{ha}^{-1}$, sem corretivos, que resultou em $137 \mathrm{~kg} \mathrm{ha}^{-1}$ a mais de soja que a média para o uso de fertilizantes e corretivos $\left(3.811 \mathrm{~kg} \mathrm{ha}^{-1}\right)$, ou seja, resultados muito semelhantes. A ausência de resposta a aplicação de calcário e gesso também são documentados por Caires (2013), em trabalho de revisão, mostrando em vários estudos não haver ganhos em produtividade com a calagem no $1^{\circ}$ ano. Segundo o autor, fatores como disponibilidade de cátions, baixa toxicidade de $\mathrm{Al}$ e umidade adequada explicam estes altos rendimentos. No presente estudo, os teores iniciais de $\mathrm{Ca}, \mathrm{Mg}$ e ao $\mathrm{V} \%$ no solo estão adequados (3,9 e 1,4 $\mathrm{cmol}_{\mathrm{c}} \mathrm{dm}^{-3}$ e 54\%, respectivamente), e houve condição hidrica suficiente para os altos rendimentos (Figura 1).

Para as formas de implantação do fertilizante/U. ruziziensis em meio ao milho, houve significância para altura da inserção da espiga (AIE) e para a massa de mil grãos (MMG), com tendência geral de maiores valores para a modalidade de distribuição em superfície da mistura fertilizante/U. ruziziensis (Tabelas 2 e 3). A adubação usada na cultura da soja influenciou apenas a AIE no milho (Tabela 2). As demais variáveis não apresentaram diferença significativa, mostrando que o consórcio com a forrageira e diferentes formas de adição de fertilizantes ou corretivos no sistema muitas vezes não afeta a produtividade das culturas, podendo o consórcio ser utilizado sem grandes prejuízos à cultura do milho na região, o que corrobora com Buchelt et al. (2013), em estudo realizado no mesmo ano agrícola na mesma região.

A altura de plantas (AP), apesar de não significativa para os tratamentos, acompanhou os dados de AIE, que foram influenciados tanto pelo método de implantação do fertilizante/ $U$. ruziziensis como pela adubação usada anteriormente na soja. A mistura fertilizante/ $U$. ruziziensis estabelecida em superfície teve uma média superior em relação à incorporada (3 $\mathrm{cm}$ ), e isso pode ser caracterizado pela maior competitividade por espaço decorrente da melhor destruição das sementes na superfície do solo e de sua rápida germinação, e consequente acelerado crescimento. Esses dados se assemelham-se aos de Buchelt et al. (2013), em que os autores avaliaram a distribuição do fertilizante/U. ruziziensis em superfície ou incorporado com sulcador (botinha), verificaram tendência de plantas mais altas e maiores 
AIE para a aplicação em superfície. Em relação aos sistemas de adubação, nota-se que o solo corrigido com gesso agrícola obteve médias significativas, e o sistema de adubação tradicional da fazenda foi o que melhor se sobressaiu nesta variável. A maior altura da inserção da espiga é um importante fator no consórcio milho-forrageira, pois permite que a colheita mecanizada seja realizada sem maiores problemas, com a plataforma mais alta, o que diminui os riscos de embuchamento (BRAMBILLA et al., 2009).

Tabela 2. Altura de plantas de milho (AP), altura de inserção da espiga (AIE), estande de plantas (EP) e número de fileiras por espiga (NFE), em função dos sistemas de adubação e semeadura da $U$. ruziziensis. Vera-MT, safra 2011/2012. Height of corn plants (AP), height of ear insertion (IEA), plant stand (EP) and number of rows per ear (NFE), depending on the fertilization and sowing systems of U. ruziziensis. Vera-MT, 2011/2012 harvest.

\begin{tabular}{|c|c|c|c|c|}
\hline \multirow{2}{*}{$\begin{array}{l}\text { Semeadura da } U \text {. ruziziensis e } \\
\text { adubação no milho }\end{array}$} & $\mathbf{A P}$ & AIE & EP & NFE \\
\hline & \multicolumn{2}{|c|}{----(cm)---- } & mil ha ${ }^{-1}$ & \\
\hline Incorporado & $228,4 \mathrm{a}$ & $108,6 \mathrm{~b}$ & $59802 \mathrm{a}$ & $17,7 \mathrm{a}$ \\
\hline Superficial & 229,6 a & $111,7 \mathrm{a}$ & $61169 \mathrm{a}$ & $18,0 \mathrm{a}$ \\
\hline Média & 229,0 & 110,1 & 60488 & 17,8 \\
\hline $\mathrm{CV}(\%)$ & 3,19 & 5,53 & 7,71 & 6,28 \\
\hline Manejo da adubação & $\mathbf{A P}$ & AIE & EP & NFE \\
\hline Adubação apenas no milho & $223,8 \mathrm{a}$ & $105,1 \mathrm{~b}$ & $61288 \mathrm{a}$ & $17,7 \mathrm{a}$ \\
\hline PK superficial (manejo fazenda) & $232,6 \mathrm{a}$ & $118,0 \mathrm{a}$ & 59436 a & $17,7 \mathrm{a}$ \\
\hline Gesso + PK superficial & $233,0 \mathrm{a}$ & $111,0 \mathrm{ab}$ & $63510 \mathrm{a}$ & $18,0 \mathrm{a}$ \\
\hline Gesso + PK incorporado & $234,4 \mathrm{a}$ & $113,0 \mathrm{ab}$ & 59066 a & $18,5 \mathrm{a}$ \\
\hline Calcário + PK superficial & $226,8 \mathrm{a}$ & $107,0 \mathrm{~b}$ & $60740 \mathrm{a}$ & $17,1 \mathrm{a}$ \\
\hline Calcário + PK incorporado & $223,6 \mathrm{a}$ & $106,5 \mathrm{~b}$ & 58888 a & $18,2 \mathrm{a}$ \\
\hline Média & 229,0 & 110,1 & 60488 & 17,8 \\
\hline $\mathrm{CV}(\%)$ & 3,34 & 6,74 & 6,78 & 5,80 \\
\hline
\end{tabular}

Nota: $\mathrm{PK}=400 \mathrm{~kg} \mathrm{ha}^{-1}$ do formulado $00-18-18+8 \mathrm{~S}+16 \mathrm{Ca}+0,8 \mathrm{Zn}+0,16 \mathrm{~B}+0,07 \mathrm{Cu}+0,18 \mathrm{Mn}$; Gesso $=3,0 \mathrm{t}$ $\mathrm{ha}^{-1} \mathrm{e}$ Calcário 2,0 $\mathrm{t} \mathrm{ha}^{-1}$. Médias seguidas da mesma letra, nas colunas, não diferem, estatisticamente, entre si, a 10\%, pelo teste Tukey. Note: $P K=400 \mathrm{~kg} \mathrm{ha} a^{-1}$ of the formula $00-18-18+8 S+16 \mathrm{Ca}+0.8 \mathrm{Zn}+0.16 \mathrm{~B}+0.07 \mathrm{Cu}$

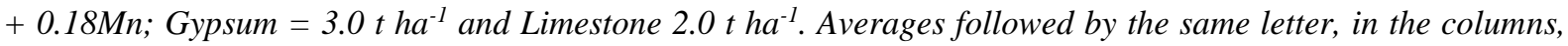
do not differ, statistically, from each other, by 10\%, by the Tukey test.

Fonte: Autoria própria. Own authorship.

O estande (EP) e o número de fileiras por espiga (NFE) acompanharam a tendência da AIE, em que a aplicação superficial da mistura fertilizante/U. ruziziensis resultou em acréscimo de 1.367 plantas ha ${ }^{-1}$ e estas com espigas apresentando maior número de fileiras. Isto pode ser resultado da menor competição entre milho e $U$. ruziziensis por nutrientes na linha de semeadura, já que o fator água não foi limitante, pois as chuvas foram bem distribuídas em março de 2012 (45, 89 e 87 mm, a cada dez dias, respectivamente). Esta observação pode ser amparada pelos dados do manejo da adubação, em que a adubação apenas no milho, com $650 \mathrm{~kg} \mathrm{ha}^{-1}$ do formulado resultou em maior EP que a aplicação apenas de $250 \mathrm{~kg} \mathrm{ha}^{-1}$ de fertilizante na linha. 
Tabela 3. Número de grãos por fileira (NGF), massa de 1000 grãos (MMG), produtividade do milho (PD) e matéria seca da U. ruziziensis (MSR), em função dos sistemas de adubação da soja e semeadura da $U$. ruziziensis/adubação do milho. Vera-MT, safra 2011/2012. Number of grains per row (NGF), mass of 1000 grains $(M M G)$, corn productivity (PD) and dry matter of $U$. ruziziensis (MSR), depending on the soy fertilization and sowing systems of $U$. ruziziensis/fertilization of corn. Vera-MT, 2011/2012 harvest.

\begin{tabular}{lcccc}
\hline \multirow{2}{*}{$\begin{array}{l}\text { Semeadura da } \boldsymbol{U} \text {. ruziziensis e } \\
\text { adubação no milho }\end{array}$} & NGF & MMG & PD & MSR \\
\cline { 2 - 5 } Incorporado & & \multicolumn{2}{c}{$(\mathrm{g})$} & \multicolumn{2}{c}{$\left(\mathrm{kg} \mathrm{ha}^{-1}\right)$} \\
\hline Superficial & $33,7 \mathrm{a}$ & $268,6 \mathrm{~b}$ & $8087,4 \mathrm{a}$ & $8070,2 \mathrm{a}$ \\
\hline Média & $33,6 \mathrm{a}$ & $299,7 \mathrm{a}$ & $8127,0 \mathrm{a}$ & $8380,3 \mathrm{a}$ \\
\hline CV $(\%)$ & 33,7 & 274,1 & 8107,2 & 8230,3 \\
\hline Manejo da adubação & NGF & MMG & PD & MSB \\
\hline Adubação apenas no milho & $32,0 \mathrm{a}$ & $264,3 \mathrm{a}$ & $7678,0 \mathrm{a}$ & $7826,8 \mathrm{a}$ \\
PK superficial (manejo fazenda) & $34,7 \mathrm{a}$ & $270,9 \mathrm{a}$ & $7989,0 \mathrm{a}$ & $7473,1 \mathrm{a}$ \\
Gesso + PK superficial & $33,0 \mathrm{a}$ & $275,7 \mathrm{a}$ & $8642,8 \mathrm{a}$ & $7836,1 \mathrm{a}$ \\
Gesso + PK incorporado & $34,1 \mathrm{a}$ & $281,0 \mathrm{a}$ & $8758,7 \mathrm{a}$ & $8413,1 \mathrm{a}$ \\
Calcário + PK superficial & $34,3 \mathrm{a}$ & $276,4 \mathrm{a}$ & $7801,1 \mathrm{a}$ & $9652,6 \mathrm{a}$ \\
Calcário + PK incorporado & $34,0 \mathrm{a}$ & $276,3 \mathrm{a}$ & $7774,0 \mathrm{a}$ & $8179,9 \mathrm{a}$ \\
\hline Média & 33,7 & 274,1 & 8107,2 & 8230,3 \\
\hline CV $(\%)$ & 7,05 & 6,52 & 15,32 & 34,75 \\
\hline
\end{tabular}

Nota: $\mathrm{PK}=400 \mathrm{~kg} \mathrm{ha}^{-1}$ do formulado $00-18-18+8 \mathrm{~S}+16 \mathrm{Ca}+0,8 \mathrm{Zn}+0,16 \mathrm{~B}+0,07 \mathrm{Cu}+0,18 \mathrm{Mn}$; Gesso = 3,0 t $\mathrm{ha}^{-1} \mathrm{e}$ Calcário 2,0 $\mathrm{t} \mathrm{ha}^{-1}$. Médias seguidas da mesma letra, nas colunas, não diferem, estatisticamente, entre si, a $10 \%$, pelo teste Tukey. Note: $P K=400 \mathrm{~kg} \mathrm{ha} a^{-1}$ of the formula $00-18-18+8 S+16 \mathrm{Ca}+0.8 \mathrm{Zn}+0.16 \mathrm{~B}+0.07 \mathrm{Cu}$

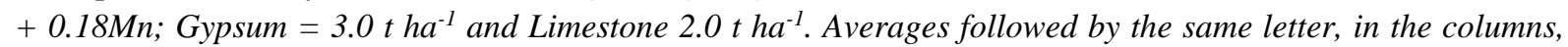
do not differ, statistically, from each other, by 10\%, by the Tukey test.

Fonte: Autoria própria. Own authorship.

Apesar do número de grãos por fileira (NGF) ser um pouco menor quando a mistura fertilizante/U. ruziziensis foi aplicada superficialmente, a massa de mil grãos (MMG), ao contrário, foi maior, com 31,1 g a mais (Tabela 3). Para a adubação residual da soja, os grãos mais pesados no milho foram observados no tratamento gesso mais PK incorporado, resultado possivelmente, do gesso agrícola que fornece $\mathrm{Ca}$ e $\mathrm{S}$ e da incorporação do fertilizante na semeadura da soja que, com a menor umidade do solo na época de enchimento de grãos do milho, pôde ser melhor aproveitado, já que no final do ciclo, as chuvas ficaram mais escassas, com $32 \mathrm{~mm}$ nos últimos dez dias de maio, $4 \mathrm{~mm}$ nos primeiros dez dias de junho e uma chuva isolada em 22/6, de $34 \mathrm{~mm}$ (Figura 1).

Esse conjunto de fatores resultou em incrementos na produtividade de grãos. Quando a mistura fertilizante/U. ruziziensis foi aplicada superficialmente a produtividade foi um pouco superior $\left(40 \mathrm{~kg} \mathrm{ha}^{-1}\right)$, resultado decorrente da menor competição na linha entre milho e $U$. ruziziensis, o que corrobora com Brambilla et al. (2009) e Buchelt et al. (2013). Para o efeito residual da adubação da soja, os dois tratamentos com o uso de gesso na correção do solo resultaram em incremento de $890 \mathrm{~kg} \mathrm{ha}^{-1}$ em relação aos demais manejos, que apresentaram produtividades próximas $7.800 \mathrm{~kg} \mathrm{ha}^{-1}$. Os resultados acompanham a tendência da MMG, em que o tratamento gesso e fertilizante incorporado na soja melhorou a massa dos grãos o que, 
provavelmente veio influenciar diretamente a produtividade do milho, devido ao fornecimento de nutrientes pelo gesso e ao melhor aproveitamento do fertilizante residual que estava enterrado e em contato com a umidade do solo.

A $U$. ruziziensis semeada a lanço teve maior produtividade de massa em comparação com a incorporada na linha, resultado da melhor distribuição das plantas da forrageira sobre a superfície do solo, o que resultou em mais espaço para crescimento, menor competição por fertilizante e água (Tabela 3). Para o efeito residual da soja, os melhores resultados de produtividade de capim foram para a aplicação de gesso ou calcário na soja, o que favoreceu o desenvolvimento da forrageira, que tem sistema radicular agressivo e consegue aproveitar um maior volume de solo, favorecendo a reciclagem de nutrientes no sistema.

No milho de segundo ano, após colheita da soja não apresentou diferença entre os tratamentos, porém ainda existiu efeito positivo da aplicação de gesso em relação aos demais tratamentos, como pode ser visto nos dois tratamentos com gesso (Tabela 4), que foi $6060 \mathrm{~kg}$ $\mathrm{ha}^{-1}$, superando a média dos demais tratamentos foi de $5760 \mathrm{~kg} \mathrm{ha}^{-1}$, após praticamente 1,5 anos da aplicação do produto, justificando o uso do corretivo.

Tabela 4. Altura de plantas de milho (AP), altura de inserção da espiga (AIE), diâmetro da espiga (DE), comprimento da espiga (CE), número de fileiras por espiga (NFE), massa de mil grãos (MMG), produtividade (PD) em função dos sistemas de adubação da soja e do milho. Vera-MT, safra 2012/13. Height of corn plants (AP), height of ear insertion (IEA), ear diameter (DE), ear length (CE), number of rows per ear (NFE), mass of a thousand grains ( $M M G)$, productivity (PD) as a function of soybean and corn fertilization systems. Vera-MT, 2012/13 harvest.

\begin{tabular}{|c|c|c|c|c|c|c|c|}
\hline \multirow{2}{*}{ Manejo da adubação } & $\mathbf{A P}$ & AIE & DE & $\mathbf{C E}$ & NFE & MMG & PD \\
\hline & \multicolumn{4}{|c|}{--------------- $(\mathrm{cm})$-------------- } & & (g) & $\left(\mathrm{kg} \mathrm{ha}^{-1}\right)$ \\
\hline Adubação apenas no milho & $230,6 \mathrm{a}$ & $117,6 \mathrm{a}$ & 4,70 & $15,20 \mathrm{a}$ & $16,6 \mathrm{a}$ & $292,9 \mathrm{a}$ & $5830,2 \mathrm{a}$ \\
\hline $\begin{array}{l}\text { PK superficial (manejo } \\
\text { fazenda) }\end{array}$ & $228,7 \mathrm{a}$ & $111,9 \mathrm{a}$ & 4,58 & $15,55 \mathrm{a}$ & $16,4 \mathrm{a}$ & 298,3 a & $5804,8 \mathrm{a}$ \\
\hline Gesso + PK superficial & $231,6 \mathrm{a}$ & 116 & 4,73 & 15 , & $16,5 \mathrm{a}$ & $290,8 \mathrm{a}$ & $5923,5 \mathrm{a}$ \\
\hline Gesso + PK incorporado & $233,3 \mathrm{a}$ & $112,2 \mathrm{a}$ & 4,82 & $15,07 \mathrm{a}$ & $16,5 \mathrm{a}$ & $311,5 \mathrm{a}$ & $6090,3 \mathrm{a}$ \\
\hline Calcário + PK superficial & 230,6 a & $140,1 \mathrm{a}$ & 4,81 & $16,10 \mathrm{a}$ & $16,9 \mathrm{a}$ & $301,5 \mathrm{a}$ & $5238,9 \mathrm{a}$ \\
\hline Calcário + PK incorporado & $231,9 \mathrm{a}$ & $115,6 \mathrm{a}$ & 4,70 & $15,65 \mathrm{a}$ & $16,1 \mathrm{a}$ & $298,5 \mathrm{a}$ & $6260,7 \mathrm{a}$ \\
\hline Média & 231,1 & 119,0 & 4,72 & 15,44 & 16,5 & 299,5 & 5858,0 \\
\hline$\overline{\mathrm{CV} \%}$ & 1,40 & 19,0 & 2,67 & 4,76 & 3,87 & 4,87 & 10,97 \\
\hline
\end{tabular}

Nota: $\mathrm{PK}=400 \mathrm{~kg} \mathrm{ha}^{-1}$ do formulado $00-18-18+8 \mathrm{~S}+16 \mathrm{Ca}+0,8 \mathrm{Zn}+0,16 \mathrm{~B}+0,07 \mathrm{Cu}+0,18 \mathrm{Mn}$; Gesso = 3,0 t $\mathrm{ha}^{-1} \mathrm{e}$ Calcário 2,0 $\mathrm{t} \mathrm{ha}^{-1}$. Médias seguidas da mesma letra, nas colunas, não diferem, estatisticamente, entre si, a $10 \%$, pelo teste Tukey. Note: $P K=400 \mathrm{~kg} \mathrm{ha} a^{-1}$ of the formula $00-18-18+8 S+16 \mathrm{Ca}+0.8 \mathrm{Zn}+0.16 \mathrm{~B}+0.07 \mathrm{Cu}$

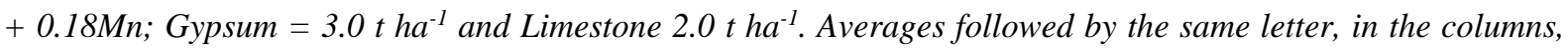
do not differ, statistically, from each other, by 10\%, by the Tukey test.

Fonte: Autoria própria. Own authorship.

Assim como no primeiro ano, o melhor tratamento foi gesso e PK incorporado na soja (safra anterior), resultando em dois anos consecutivos de maiores produtividades para este tratamento, o que, como discutido, se deve a incorporação do fertilizante na soja, e na época em que o milho demanda nutrientes, este fertilizante ainda está em contato com água 
disponível (maior profundidade do fertilizante), favorecendo a absorção devido à melhor difusão, pois sabe-se que só há absorção na presença de água disponível. Também como no primeiro ano de cultivo, esse tratamento apresentou a maior MMG em relação aos demais tratamentos. A menor produtividade média do segundo ano de cultivo (5.858 $\mathrm{kg} \mathrm{ha}^{-1}$ ) em relação ao primeiro (8.107 $\mathrm{kg} \mathrm{ha}^{-1}$ ) é explicada pela falta de chuvas. Na safra agrícola 2011/12, o acumulado para os meses de março, abril, maio e junho foi de 222,8; 110,2; 54,2 e $34,6 \mathrm{~mm}$, o que possivelmente provocou pequena competição por água no sistema. Para o segundo ano de cultivo, para os meses de março e abril, a precipitação foi de 361,0 e 177,2 $\mathrm{mm}$, não chovendo em maio e junho, o que aumentou a competição entre o milho e a $U$. ruziziensis e reduziu a produtividades de grãos no sistema.

Após o cultivo da soja e do milho segunda safra, o solo apresentou diferenças significativas nos teores de $\mathrm{K}$, na relação $\mathrm{Ca}: \mathrm{Mg}$ e nas porcentagens de $\mathrm{K}$ e de $\mathrm{Ca}$ em relação a capacidade de troca de cátions (CTC) do solo, na profundidade de 0-0,2 m, sendo os efeitos mais pronunciados na profundidade de $0,1-0,2 \mathrm{~m}$ do que na profundidade de $0-0,1 \mathrm{~m}$ (Tabela 5).

Aparentemente houve pequena movimentação de $\mathrm{K}$ das camadas de 0-0,1 e 0,1-0,2 m para maiores profundidades nos tratamentos em que se utilizou gesso, resultado da formação de $\mathrm{K}_{2} \mathrm{SO}_{4}{ }^{0}$, composto neutro de alta mobilidade no perfil (ALVAREZ V. et al., 1999) e dos altos índices pluviométricos. A média dos teores de $\mathrm{K}\left(\mathrm{mg} \mathrm{dm}^{-3}\right)$ na profundidade de $0-0,2 \mathrm{~m}$ (Tabela 6) nos tratamentos com gesso foi $43,7 \mathrm{mg} \mathrm{dm}^{-3}$ e a média dos demais tratamentos $\left(59,1 \mathrm{mg} \mathrm{dm}^{-3}\right)$, valor $26 \%$ menor $\left(15,4 \mathrm{mg} \mathrm{dm}^{-3}\right)$ que dos demais tratamentos, sendo o mesmo comportamento observado para a saturação por K na CTC. Isto obviamente está relacionado à movimentação vertical e também à maior exportação de $\mathrm{K}$, decorrente das maiores produtividades da soja e do milho nestes tratamentos com gesso. A lixiviação de $\mathrm{K}$ trocável pelo uso de gesso possa ocorrer, porém em pequena magnitude (CAIRES et al., 2002). Os teores de Ca na profundidade de 0-0,2 m, apesar de não significativos, foram maiores nos tratamentos com gesso, seguidos pela aplicação de calcário e depois pela ausência de corretivos, com valores próximos a 4,1; 3,4;3,3 $\mathrm{cmol}_{\mathrm{c}} \mathrm{dm}^{-3}$, respectivamente, estando de acordo com os tratamentos. Os valores de $\mathrm{Mg}$, Al e a CTC não foram afetados, com pequenas variações, o que é comum ao trabalhar-se com análises de solo. A relação $\mathrm{Ca} / \mathrm{Mg}$ foi maior para os tratamentos com gesso na profundidade de $0,1-0,2 \mathrm{~m}$, assim como na média das duas profundidades (0-0,2 m), decorrente da aplicação de $510 \mathrm{~kg} \mathrm{ha}^{-1} \mathrm{de} \mathrm{Ca}$, via gesso e de sua movimentação para a camada 0,1-0,2 m. Na profundidade de 0,1-0,2 e 0-0,2 m, a relação $\mathrm{Ca} / \mathrm{Mg}$ nos tratamentos com gesso foi de 2,8/1 e 2,9/1, enquanto para os demais tratamentos foi de 2,1/1 e 2,3/1, respectivamente, mostrando que o cálcio se movimentou para a segunda camada, deslocando o $\mathrm{K}$ e ficando retido nos pontos de troca (CTC). O mesmo comportamento foi observado para a saturação por Ca na CTC, resultado da movimentação do nutriente no perfil. Assim, apesar de o gesso agrícola ser um produto de extrema eficiência na agricultura, deve-se tomar o devido cuidado com seu uso e aliar o mesmo a um sistema que tenha plantas de cobertura capazes de reciclar nutrientes movimentados, devido a sua aplicação. 
Tabela 5. Resultado da análise química do solo na profundidade de 0-10 cm e 10-20 cm na área um ano após o início do experimento em função dos sistemas de adubação da soja e do milho na safra 2012/13. Vera-MT, setembro de 2012. Result of the chemical analysis of the soil at depths of 0-10 cm and 10-20 cm in the area one year after the beginning of the experiment due to the fertilization systems of soybeans and corn in the 2012/13 harvest. Vera - MT, September 2012.

\begin{tabular}{|c|c|c|c|c|c|c|c|c|c|c|c|c|c|c|c|}
\hline \multirow[b]{2}{*}{ TRATAMENTOS } & \multicolumn{15}{|c|}{$0-0,1 \mathrm{~m}$} \\
\hline & $\mathbf{p H}\left(\mathrm{H}_{20)}\right.$ & $\mathbf{P}$ & $\mathbf{K}$ & $\mathrm{Ca}+\mathrm{Mg}$ & $\mathbf{C a}$ & Mg & Al & $\mathbf{H}+\mathbf{A l}$ & $\mathrm{CTC}_{(\mathrm{pH})}$ & $\mathrm{Ca} / \mathrm{Mg}$ & $\mathbf{V}$ & SAT. K & $\begin{array}{c}\text { SAT. } \\
\text { Ca }\end{array}$ & SAT. Mg & MO \\
\hline & & \multicolumn{2}{|c|}{$\mathrm{mg} \mathrm{dm}{ }^{-3}$} & \multicolumn{7}{|c|}{ - } & \multicolumn{4}{|c|}{ - } & $\mathrm{g} \mathrm{kg}^{-1}$ \\
\hline Controle & 5,8 & 8,0 & 56,1 & 4,9 & 3,4 & 1,4 & 0,04 & 4,1 & 9,2 & 2,3 & 54,2 & 1,6 & 36,8 & 16,1 & 26,7 \\
\hline Pk.sup & 6,0 & 9,4 & 67,5 & 4,6 & 3,6 & 1,5 & 0,02 & 3,8 & 8,6 & 2,5 & 55,7 & 2,0 & 41,8 & 16,9 & 26,2 \\
\hline Gesso- Pk.sup & 6,4 & 10,1 & 53,0 & 5,5 & 4,4 & 1,4 & 0,03 & 4,4 & 10,0 & 3,1 & 56,4 & 1,4 & 44,1 & 14,3 & 28,6 \\
\hline Gesso- Pk.inc & 6,1 & 10,9 & 46,8 & 5,0 & 4,2 & 1,4 & 0,03 & 4,0 & 9,1 & 2,9 & 56,3 & 1,4 & 45,8 & 15,9 & 27,2 \\
\hline Calcario- Pk.sup & 6,3 & 9,1 & 59,0 & 4,9 & 3,6 & 1,5 & 0,03 & 3,7 & 8,7 & 2,5 & 57,3 & 1,7 & 40,9 & 16,6 & 28,8 \\
\hline Calcario- Pk.inc & 6,3 & 10,2 & 65,4 & 5,2 & 4,0 & 1,5 & 0,02 & 4,0 & 9,4 & 2,7 & 56,5 & 1,9 & 42,2 & 16,1 & 29,8 \\
\hline Media & 6,2 & 9,6 & 58,0 & 5,0 & 3,9 & 1,4 & 0,03 & 4,0 & 9,2 & 2,7 & 56,1 & 1,7 & 41,9 & 16,0 & 27,9 \\
\hline $\mathrm{Cv}$ & 6,55 & 25,98 & 20,6 & 18,35 & 16,44 & 2,37 & 47,95 & 14,68 & 12,22 & 14,83 & 9,60 & 22,89 & 10,70 & 11,09 & 13,98 \\
\hline \multirow[t]{2}{*}{ DMS } & 0,82 & 5,05 & 24,2 & 1,86 & 1,28 & 0,07 & 0,03 & 1,19 & 2,26 & 0,80 & 10,90 & 0,77 & 9,09 & 3,59 & 7,90 \\
\hline & \multicolumn{15}{|c|}{$0,1-0,2 \mathrm{~m}$} \\
\hline Controle & 6,0 & 4,5 & $49,7 \mathrm{ab}$ & 4,7 & 3,2 & 1,4 & 0,03 & 4,1 & 8,9 & $2,2 a b$ & 53,3 & $1,5 \mathrm{abc}$ & $36,3 \mathrm{ab}$ & 16,4 & 24,9 \\
\hline Pk.sup & 5,9 & 4,7 & $65,7 \mathrm{a}$ & 4,0 & 3,0 & 1,4 & 0,04 & 3,6 & 7,8 & $2,1 \mathrm{~b}$ & 53,6 & $2,1 \mathrm{a}$ & $38,4 \mathrm{ab}$ & 18,5 & 23,7 \\
\hline Gesso- Pk.sup & 6,0 & 7,2 & $41,2 \mathrm{~b}$ & 4,8 & 4,2 & 1,4 & 0,03 & 4,0 & 8,9 & $2,9 \mathrm{a}$ & 55,0 & $1,2 \mathrm{bc}$ & 46,8 a & 16,1 & 25,1 \\
\hline Gesso- Pk.inc & 6,4 & 6,7 & $33,7 \mathrm{~b}$ & 4,8 & 3,7 & 1,4 & 0,03 & 4,6 & 9,5 & $2,6 a b$ & 50,5 & $0,9 \mathrm{c}$ & $38,6 \mathrm{ab}$ & 14,9 & 22,3 \\
\hline Calcario- Pk.sup & 6,1 & 5,5 & $52,6 \mathrm{ab}$ & 4,2 & 3,1 & 1,4 & 0,04 & 4,6 & 8,9 & $2,2 \mathrm{ab}$ & 47,9 & $1,5 \mathrm{abc}$ & $34,7 \mathrm{~b}$ & 16,1 & 24,9 \\
\hline Calcario- Pk.inc & 6,3 & 6,3 & $56,7 \mathrm{ab}$ & 4,3 & 3,0 & 1,4 & 0,04 & 4,3 & 8,8 & $2,1 \mathrm{~b}$ & 48,5 & $1,8 \mathrm{ab}$ & $34,0 \mathrm{~b}$ & 17,2 & 22,9 \\
\hline Media & 6,1 & 5,8 & 49,9 & 4,5 & 3,4 & 1,4 & 0,03 & 4,2 & 8,8 & 2,4 & 51,4 & 1,5 & 38,1 & 16,5 & 23,9 \\
\hline $\mathrm{Cv}$ & 6,50 & 47,46 & 22,86 & 24,98 & 19,01 & 3,27 & 51,92 & 13,38 & 16,21 & 16,28 & 11,03 & 22,81 & 15,08 & 13,28 & 10,25 \\
\hline DMS & 0,77 & 5,56 & 23,13 & 2,24 & 1,29 & 0,09 & 0,04 & 1,14 & 2,89 & 0,78 & 11,50 & 0,70 & 11,65 & 4,44 & 4,97 \\
\hline
\end{tabular}

Nota: $\mathrm{PK}=400 \mathrm{~kg} \mathrm{ha}^{-1}$ do formulado 00-18-18+8S+16Ca +0,8Zn+0,16B +0,07Cu +0,18Mn; Gesso = 3,0 $\mathrm{t}^{-1} \mathrm{e}^{-1}$ Calcário 2,0 $\mathrm{t}$ ha ${ }^{-1}$. Médias seguidas da mesma letra, nas colunas, não diferem, estatisticamente, entre si, a $10 \%$, pelo teste Tukey. Note: $P K=400 \mathrm{~kg} \mathrm{ha-1}$ of the formula $00-18-18+8 S+16 C a+0.8 Z n+0.16 B+0.07 C u+0.18 M n$;

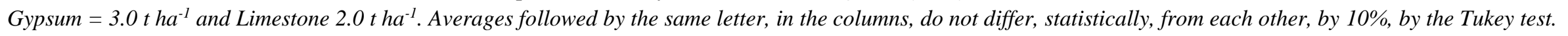

Fonte: Autoria própria. Own authorship. 
Tabela 6. Resultado da análise química do solo na profundidade de 0-20 $\mathrm{cm}$ na área um ano após o início do experimento em função dos sistemas de adubação da soja e do milho na safra 2012/13. Vera - MT, setembro de 2012. Result of the chemical analysis of the soil at depths of $0-10 \mathrm{~cm}$ and 10-20 cm in the area one year after the beginning of the experiment due to the fertilization systems of soybeans and corn in the 2012/13 harvest. Vera - MT, September 2012.

\begin{tabular}{|c|c|c|c|c|c|c|c|c|c|c|c|c|c|c|c|}
\hline \multirow{4}{*}{ TRATAMENTOS } & \multicolumn{15}{|c|}{$0-0,1 \mathrm{~m}$} \\
\hline & $\mathbf{p} \mathbf{H}_{(\mathrm{H} 2 \mathrm{O})}$ & $\mathbf{P}$ & $\mathbf{K}$ & $\mathrm{Ca}+\mathrm{Mg}$ & $\mathbf{C a}$ & Mg & Al & $\mathbf{H}+\mathbf{A l}$ & $\mathrm{CTC}_{(\mathrm{pH} 7)}$ & $\mathrm{Ca} / \mathrm{Mg}$ & $\mathbf{V}$ & SAT. K & $\begin{array}{l}\text { SAT. } \\
\text { Ca }\end{array}$ & SAT. Mg & MO \\
\hline & \multicolumn{3}{|c|}{$m g \mathrm{dm}^{-3}$} & ------ & - & $--\mathrm{cm}$ & $\mathrm{lc} \mathrm{dm}^{-3}$ & 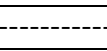 & -ב--- & & \multicolumn{4}{|c|}{------------------- $\%$----------------------- } & $\mathrm{g} \mathrm{kg}^{-1}$ \\
\hline & \multicolumn{15}{|c|}{$0-0,2 \mathrm{~m}$} \\
\hline Controle & 5,9 & 6,2 & $52,9 \mathrm{ab}$ & 4,8 & 3,3 & 1,4 & 0,03 & 4,1 & 9,0 & $2,3 \mathrm{~b}$ & 53,8 & $1,5 \mathrm{abc}$ & $36,5 \mathrm{~b}$ & 16,2 & 25,8 \\
\hline Pk.sup & 5,9 & 7,1 & 66,6 a & 4,3 & 3,3 & 1,4 & 0,03 & 3,7 & 8,2 & $2,3 \mathrm{~b}$ & 54,6 & $2,1 \mathrm{a}$ & $40,1 \mathrm{ab}$ & 17,7 & 25,0 \\
\hline Gesso- Pk.sup & 6,2 & 8,6 & $47,1 \mathrm{ab}$ & 5,1 & 4,3 & 1,4 & 0,03 & 4,2 & 9,4 & $3,0 \mathrm{a}$ & 55,7 & $1,3 \mathrm{bc}$ & $45,5 \mathrm{a}$ & 15,2 & 26,8 \\
\hline Gesso- Pk.inc & 6,2 & 8,8 & $40,3 \mathrm{~b}$ & 4,9 & 3,9 & 1,4 & 0,03 & 4,3 & 9,3 & $2,8 \mathrm{ab}$ & 53,4 & $1,2 \mathrm{c}$ & $42,2 \mathrm{ab}$ & 15,4 & 24,7 \\
\hline Calcario- Pk.sup & 6,2 & 7,3 & $55,8 \mathrm{ab}$ & 4,5 & 3,3 & 1,4 & 0,03 & 4,2 & 8,8 & $2,3 \mathrm{~b}$ & 52,6 & $1,6 \mathrm{acb}$ & $37,8 \mathrm{~b}$ & 16,3 & 26,8 \\
\hline Calcario- Pk.inc & 6,3 & 8,2 & $61,1 \mathrm{ab}$ & 4,8 & 3,5 & 1,5 & 0,03 & 4,1 & 9,1 & $2,4 \mathrm{ab}$ & 52,5 & $1,9 \mathrm{ab}$ & $38,1 \mathrm{~b}$ & 16,6 & 26,3 \\
\hline Media & 6,1 & 7,7 & 54,0 & 4,7 & 3,6 & 1,4 & 0,03 & 4,1 & 9,0 & 2,5 & 53,8 & 1,6 & 40,0 & 16,3 & 25,9 \\
\hline $\mathrm{Cv}$ & 6,50 & 31,36 & 19,44 & 20,19 & 15,43 & 2,54 & 41,03 & 10,36 & 12,64 & 13,32 & 8,86 & 20,90 & 7,85 & 10,37 & 10,42 \\
\hline DMS & 0,69 & 4,89 & 21,25 & 1,94 & 1,13 & 0,07 & 0,03 & 0,86 & 2,30 & 0,68 & 9,65 & 0,67 & 6,36 & 3,41 & 5,47 \\
\hline
\end{tabular}

Nota: $\mathrm{PK}=400 \mathrm{~kg} \mathrm{ha}^{-1}$ do formulado 00-18-18 + 8S+16Ca +0,8Zn + 0,16B + 0,07Cu + 0,18Mn; Gesso = 3,0 t ha ${ }^{-1}$ e Calcário 2,0 $\mathrm{t}$ ha ${ }^{-1}$. Médias seguidas da mesma letra, nas colunas, não diferem, estatisticamente, entre si, a $10 \%$, pelo teste Tukey. Note: $P K=400 \mathrm{~kg} \mathrm{ha} a^{-1}$ of the formula $00-18-18+8 S+16 C a+0.8 Z n+0.16 B+0.07 C u+0.18 M n$; Gypsum $=3.0 \mathrm{t} \mathrm{ha} \mathrm{t}^{-1}$ and Limestone $2.0 \mathrm{th} \mathrm{h}^{-1}$. Averages followed by the same letter, in the columns, do not differ, statistically, from each other, by $10 \%$, by the Tukey test.

Fonte: Autoria própria. Own authorship. 


\section{CONCLUSÃO}

Em solo de fertilidade construída, correções e fertilizações diferenciadas não provocam alterações significativas nos componentes de produção e a produtividade final das culturas em dois anos;

A distribuição de $U$. ruziziensis em superfície em área total antes de semear o milho aumenta a altura de inserção de espigas, a massa de mil grãos e a produtividade do milho e a massa do capim.

No solo a aplicação de gesso superficialmente movimenta potássio no perfil do solo, aumenta os teores de cálcio em relação à CTC do solo e melhora a relação cálcio/magnésio na camada de $0-0,2 \mathrm{~m}$.

\section{AGRADECIMENTOS}

Ao apoio financeiro projeto FAPEMAT/CNPQ PROCESSO No. 477794/2011 (Pronen) e aos proprietários da fazenda Dassi (Vera-MT).

\section{REFERÊNCIAS BIBLIOGRÁFICAS}

ALVAREZ V, V. H.; DIAS, L. E.; RIBEIRO, A. C.; SOUZA, R. B. Uso de gesso agrícola. In: RIBEIRO, A. C.; GUIMARÃES, P. T. G.; ALVAREZ V, V. H. Recomendação para o uso de corretivos e fertilizantes em Minas Gerais. 5. Aproximação. Viçosa, MG: Comissão de Fertilidade do Solo do Estado de Minas Gerais, 1999. cap. 10 , p. 67-78

BERGAMIN, A. C.; SCHLINDWEIN, J. A.; VENTUROSO, L. R.; VALADÃO JÚNIOR, D. D.; CARON, B. O.; SCHMIDT, D. Respostas de duas cultivares de soja à adubação a lanço e em sulco, no município de Rolim de Moura/RO. Revista Ciências Agrárias, Belém, v. 1, n. 50, p.155-166, 2008.

BRAMBILlA, J. A.; LANGE, A.; BUCHELT, A. C.; MASSAROTO, J. A. Produtividade de milho safrinha no sistema de integração lavoura-pecuária, na região de sorriso, mato grosso. Revista Brasileira de Milho e Sorgo, Sete Lagoas, v. 8, n. 3, p.263-274, 2009.

BUCHElT, A. C.; LANGE, A.; BILIBIO, F.; ZANUZO, M. R.; CAVALli, E. Milho safrinha integrado com brachiaria ruziziensise mecanismos de aplicação do fertilizante. Revista de Ciências Agroambientais, Alta Floresta, v. 11, n. 2, p.143-151, 2013.

CAIRES, E. F. Correção da acidez do solo em sistema plantio direto. Piracicaba: IPNI, Informações Agronômicas, Piracicaba, n. 141, p.1-13, 2013. Disponível em: http://www.ipni.net/publication/ia-

brasil.nsf/0/4A4F64F9876B415683257B3F00708191/\$FILE/Page1-13-141.pdf. Acesso em 16 nov. 2020.

CAIRES, E. F.; FELDHAUS, I. C.; BARTH, G. e GARBUIO, F. J. Lime and gypsum application on the wheat crop. Scientia Agricola, Piracicaba, v. 59, n. 2, p.357-364, 2002. 
DUARTE, A.P.; CANTARELLA, H. Adubação em sistemas de produção de soja e milho safrinha. In: SEMINÁRIO NACIONAL DO MILHO SAFRINHA: RUMO A ESTABILIDADE, 9., 2007, Dourados, 2007. Anais [...] Dourados: Embrapa Agropecuária Oeste, 2007. p.44-61. (Embrapa Agropecuária Oeste. Documentos, 89).

DUARTE, A. P.; ABREU, M. F.; FRANCISCO, E. A. B.; GITTI, D. C.; BARTH, G.; KAPPES, C. Concentração e exportação de nutrientes nos grãos de Milho. Informações agronômicas, Piracicaba, n. 163, p.12-16, 2018. Disponível em: <http://www.ipni.net/publication/ia-brasil.nsf/0/59DBFDA8B79

1955E832583290046AA6F/\$FILE/Page12-16-163.pdf>. Acesso em: 09 nov. 2020.

EMPRESA BRASILEIRA DE PESQUISA AGROPECUÁRIA - EMBRAPA. Manual de análises químicas do solo, plantas e fertilizantes2. ed. rev. ampl. .Brasília: Embrapa Informação Tecnológica, 2009. 627 p.

EMPRESA BRASILEIRA DE PESQUISA AGROPECUÁRIA - EMBRAPA. Sistema brasileiro de classificação de solos. 3.ed. Brasília: 2013. 353 p.

FERREIRA, D. F. Sisvar: A computer analysis system to fixed effects split plot type designs.

Revista Brasileira de Biometria, São Paulo, v. 37, n. 4, p.529-535, 2019. Disponível em: Doi: 10.28951/rbb.v37i4.450. Acesso em: 09 nov. 2020.

FOLONI, J. S. S.; ROSOLEM, C. A. Produtividade e acúmulo de potássio na soja em função da antecipação da adubação potássica no sistema plantio direto. Revista Brasileira de Ciências do Solo, Viçosa, v. 32, n. 4, p.1549-1561, 2008. Disponível em: Doi: 10.1590/S0100-06832008000400019. Acesso em: 09 nov. 2020.

LANGE, A.; CAVAlli, E.; PEREIRA, C. S.; CHAPLA, M. V.; FREDDI, O. S. Relações cálcio:magnésio e características químicas do solo sob cultivo de soja e milho. Nativa, Sinop, v. 9, n. 3, p.294-301, 2021. Disponível em: Doi: 10.31413/nativa. v9i3.11526. Acesso em: 30 jul. 2021.

LANGE, A.; ZANDONADI, R. S.; GOBBI, F. C. Distribuição horizontal da fertilidade do solo em sistemas de tráfego controlado com fertilização em linha. Nativa, Sinop, v. 7, n. 3, p.251-255, 2019. Disponível em: Doi: 10.31413/nativa.v7i3.7639. Acesso em: 09 nov. 2020.

NUNES R.; S.; SOUSA, D. M. G.; GOEDERT, W. J.; OLIVEIRA, L. E. Z., PAVINATO, P. S.; PINHEIRO, T. D. Distribution of Soil Phosphorus Fractions as a Function of Long-Term Soil Tillage and Phosphate Fertilization Management. Frontiers in Earth Science, v. 8, p.112, 2020. Disponível em: https://doi.org/10.3389/feart.2020.00350. Acesso em: 30 jul. 2021.

SOUSA, D. M. G.; LOBATO, E. Calagem e adubação para culturas anuais e semiperenes. In: SOUSA, D. M. G.; LOBATO, G. Cerrado: correção do solo e adubação. 2. ed. Brasília: Embrapa Informação Tecnológica, 2004. cap. 12, p. 283-315.

SOUSA, D. M. G.; REIN, T. A.; SANTOS JUNIOR, J. D. G. Manejo da Adubação Fosfatada para Culturas Anuais no Cerrado. Planaltina: Embrapa Cerrados, 2016. 10 p. (Circular técnica 33). Disponível em: https://www.infoteca.cnptia.embrapa.br/infoteca/bitstream/doc/1061419/1/CT33.pdf. Acesso em: 09 nov. 2020 
VALADÃO JUNIOR, D. D.; BERGAMIN, A. C.; VENTUROSO, L. R.; SCHLINDWEIN, J. A.; CARON, B. O.; SCHMIDT, D. Adubação fosfatada na cultura da soja em Rondônia. Scientia Agraria, Curitiba, v. 9, n. 3, p.369-375, 2008. Disponível em: https://doi.org/10.5380/rsa.v9i3.11537. Acesso em: 09 nov. 2020. 